Journal of Universal Language 3

September 2002, 113-137

\title{
Language Universals and Universal Language: The Case of the Accessibility Hierarchy in Relativization
}

\author{
Jae Jung Song \\ University of Otago
}

\begin{abstract}
This paper makes an attempt to raise the profile of linguistic typology (and linguistic-typology-based L2 acquisition research) in the context of the study of universal language (or interlinguistics). Linguistic typology, together with L2 acquisition research, can provide a useful framework in which to assess the structural neutrality of artificial or planned languages. Evidence from accessibility to relativization and L2 acquisition of relative clauses is brought to bear upon the structural neutrality of artificial languages such as Esperanto. Moreover, linguistic typology and L2 acquisition research can make useful suggestions as to what may be the preferred structural types for artificial languages. Such suggestions should be taken into account in the development of artificial languages, because these languages also are learned as L2s.
\end{abstract}

Keywords: language universals, universal language, typology, artificial language, second language acquisition 


\section{Introduction}

One of the important claims often made about an artificial language (Swales 1990) or planned language (Blanke 1985), such as Esperanto, is that, because it is not the language of any particular people or nation, it can be a truly neutral language designed for international communication (e.g., Schubert 1989, Comrie 1995, Gledhill 1998). ${ }^{1}$ The neutrality of Esperanto among the languages of the world is claimed partly on the basis of the fact that it is always learned as a second language (henceforth L2) and it is nobody's native language (henceforth NL). ${ }^{2}$ English, on the other hand, is the first language (henceforth L1) of particular peoples or nations, notwithstanding its status as the most widespread international language in the world (e.g., Crystal 1997). For this reason alone, English cannot lay claim to the kind of neutrality that Esperanto has imputed to itself. However, it is a totally different matter when it comes to the question of whether Esperanto - or any other artificial language for that matter-can live up to its claimed neutrality also in terms of linguistic structure. That is, it needs to be asked whether the linguistic structure of Esperanto is so neutral with respect to the languages of the world that "the burden of language learning" is spread in an equitable way (c.f., Maxwell 1989: 103).

One way to answer this question is to evaluate Esperanto in

1 Note that the term 'artificial language' is used here to refer to any artificial language designed for human international communication. Reference will frequently be made to Esperanto in this paper, because it is the most successful artificial language, spoken by more people than any other artificial language. Thus some of the comments made about Esperanto in this paper will apply equally to other artificial languages such as Occidental, Ido and Interlingua.

2 Gledhill (1998: 6), based on Lapenna et al (1974), reports that in 1974 there were 200 children from nineteen countries documented as speakers of Esperanto as their first language. However, it seems that more detailed data should be made available to confirm that these are genuine cases of first language acquisition of Esperanto. At any rate, it is safe to assume that artificial languages are learned only as L2s. 
terms of typological properties. Linguistic typology is concerned with the study of structural properties attested in the languages of the world and the limits on the structural variation within human language (i.e., language universals). Thus it is in a good position to provide a framework in which to ascertain whether Esperanto 'stands' or 'falls' structurally as a neutral language designed for human international communication. Indeed this is why Comrie (1995) drew upon linguistic typology in his brief assessment of Esperanto (and English).

In this paper, evidence not only from linguistic typology but also from L2 acquisition research carried out within the framework of linguistic typology will be brought to bear upon the structural neutrality of Esperanto (and other artificial languages). The rationale for the inclusion in this paper of L2 acquisition research is that much has been learned about L2 acquisition from the perspective of linguistic typology, and what L2 learners have been found to do or not to do will apply equally to L2 acquisition of artificial languages such as Esperanto, since these languages are learned as L2s. Thus linguistic typology, in conjunction with L2 acquisition research, can help assess the structural neutrality of artificial languages much better than it does alone. Moreover, it will be possible to make suggestions as to what may be the preferred structural types for artificial languages, because L2 acquisition research can provide much insight into what L2 learners prefer in terms of structural options or strategies.

Needless to say, the topic of this paper will demand more than an article, if not a book. What will be done here, in the interests of space, is to discuss one particular grammatical phenomenon which has been well researched in linguistic typology and which has also attracted - and will continue to attract - attention from language acquisition researchers, namely accessibility to relativization (Keenan \& Comrie 1977), and, then, to expatiate on what insight, if any, such research can provide into the study of universal language (or inter- 
linguistics in Schubert 1989). In so doing, this paper will make an attempt to raise the profile of linguistic typology (and linguistictypology-based L2 acquisition research) in the context of the study of universal language.

The remainder of this paper is divided into four sections. In section 2, a brief discussion will be provided as to how linguistic typology, coupled with language universals research, can be invoked as a general theoretical framework in which to raise questions about the language acquisition process and also to address some of the issues or problems emerging from language acquisition research. ${ }^{3}$ This will then serve as the theoretical backdrop for what follows. Moreover, linguistic typology and language universals, in the opinion of the present writer, have not been utilized in language acquisition research as much as they should have. This state of affairs, however, should not be understood to imply that linguistic typology has little to offer for these areas of linguistics (Song 2001: 318-334). Rather, it may be due to the inadequate level of discussion that linguistic typology has received within the domain of language acquisition research. For this reason also, the discussion deserves some space in a paper like the present one. In section 3, a brief account of Keenan \& Comrie's (1977) study of relative clauses will be provided as a preface to sections 4 and 5. Section 4 provides a detailed discussion of important studies in L2 acquisition of relative clauses that have been carried out within the framework of linguistic typology. Special attention will be paid to pedagogical implications of the L2 acquisition studies, especially because artificial languages are most likely to be learned as L2s in the context of formal instruction. In section 5, the structural neutrality of relativization in artificial languages will be dealt with on the basis of the preceding sections, and some implications for Esperanto and other artificial languages will also be

3 Linguistic typology, as conceptualized in this paper (also as in Comrie 1989, Song 2001), necessarily involves language universals research. Hence "language universals" in the title of this paper. 
drawn with a view to making a small general contribution to the study of universal language. The paper concludes with a brief summary in section 6 .

\section{Linguistic Typology and Language Acquisition}

The relationship between language universals and language acquisition was clearly identified very early on in the development of modern linguistic typology as was first enunciated by Jakobson in his 1941 monograph, Kindersprache, Aphasie und Allgemeine Lautgesetze (published again in 1968 in English under the title of Child language, aphasia and phonological universals). He assumed that the implicational universal of $p \supset q$ (if $p$, then $q$ ) can be dynamically interpreted with the effect that acquisition of phonological property $q$ will precede acquisition of phonological property $p$, for instance. ${ }^{4}$ Otherwise, the implicational universal of $p \supset q$ will be violated, namely $p \&-q$ (or not $q$ ). Hawkins (1987) makes an attempt to improve on Jakobson's nascent interpretation by arguing that all that can be predicted by the implicational universal of $p \supset q$ actually is that acquisition of property $q$ will either precede, or occur simultaneously with, acquisition of property $p$ because there are already numerous languages with both $p$ and $q$ as well as languages with $q$ only. For instance, children may acquire $p$ and $q$ at the same time, "thereby mirroring the adult languages that have both $[p$ and $q]$ " (Hawkins 1987: 458). Moreover, Hawkins (1987) demonstrates that the dynamic interpretation of $p \supset q$ applies not only to L1 acquisition but also to L2 acquisition. Thus the implicational universal of $p$ $\supset q$ can be understood to place a strong constraint on both the L1

\footnotetext{
${ }^{4}$ For example, the presence of voiced aspirated stops implies the presence of voiceless aspirated stops, e.g., $b^{h} \supset p^{h}$.
} 
and L2 processes to the effect that the progressions of (1a) and (1b) are permitted, whereas that of (1c) is not.

(1) a. - p \& - q $\rightarrow-$ p \& q $\rightarrow$ p \& q

b. $-\mathrm{p} \&-\mathrm{q} \rightarrow \mathrm{p} \& \mathrm{q}$

c. $-p \&-q \rightarrow * p \&-q \rightarrow p \& q$

This leads him to formulate the Principle of Universal Consistency in Acquisition: at each stage in their evolution L1 and L2 remain consistent with implicational universals derived from current synchronic evidence. Taking his cue again from Jakobson (1941), Hawkins (1987) also adds a quantitative dimension to the dynamic interpretation for the order of L1/L2 acquisition of the implicational universal of $p \supset q$ defined in (1). Given $p \supset q$, the quantity of successful production and comprehension instances in L1 or L2 of property $q$ is predicted to be greater than, or equal to, the quantity for property $p$. Though a number of issues and problems pertaining to language acquisition are dealt with in this paper, L1 acquisition per se will not be discussed any more, because artificial languages are not acquired as L1s.

\section{The Accessibility Hierarchy}

The primary objective of Keenan \& Comrie's (1977) crosslinguistic study is to examine formal constraints on relativization. They focus on the grammatical relation of the head noun in the relative clause. Based on a sample of about fifty languages Keenan \& Comrie (1977) discover that, although they vary with respect to which grammatical relations can or cannot be relativized on, languages may not do so randomly. For instance, there are no languages in their sample that cannot relativize on subject although there are languages which can relativize only on subject. In other words, all 
languages must have at least one relativization strategy whereby subjects are relativized on. This relativization strategy is referred to by Keenan \& Comrie (1977: 68) as the "primary strategy". There is also a very strong tendency for relativization strategies to apply to a continuous segment of a hierarchy of grammatical relations or the Accessibility Hierarchy (henceforth AH), defined in (2).

(2) $\mathrm{SBJ}>\mathrm{DO}>\mathrm{IO}>\mathrm{OBL}>$ GEN $>$ OCOMP

N.B.: ">" = "is more accessible to relativization than";

SBJ =subject, DO = direct object;

$\mathrm{IO}=$ indirect object; $\mathrm{OBL}=$ oblique;

$\mathrm{GEN}=$ genitive; OCOMP $=$ object of comparison

The primary strategy, which must by definition apply to subject relation, may also continue to apply down to 'lower' relations on the $\mathrm{AH}$, and at the point where it ceases to apply, other relativization strategies may or may not take over and apply to a continuous segment of the AH. Relativization strategies including the primary strategy may 'switch off' at any point on the AH but they should in principle not 'skip' on the AH. English is one of the rare languages which can relativize on all the grammatical relations on the $\mathrm{AH}$. This language thus serves as a good example by which the AH can be illustrated with respect to relativization.

(3) the girl who swam the Straits of Dover [SBJ]

(4) the girl whom the boy loved with all his heart [DO]

(5) the girl to whom the boy gave a rose $[I O]$

(6) the girl with whom the boy danced $[O B L]$

(7) the girl whose car the lady bought for her son [GEN]

(8) the girl who the boy is taller than [OCOMP]

The majority of the languages of the world, however, are not so generous as English in their relativizing possibilities. In fact, the 
very nature of the $\mathrm{AH}$ is grounded on the observation that there are more languages which can — whether by primary or non-primary relativization strategies - relativize on subject than languages which can also relativize on direct object, on direct object than also on indirect object, on indirect object than also on oblique, and so forth.

One important point follows from the preceding discussion. If a grammatical relation on the AH can be relativized on, all 'higher' grammatical relations also must be relativized on. For example, if genitive NPs are relativized on in language $X$, then a prediction can be made to the effect that subject, direct object, indirect object and oblique NPs also will be relativized on; if oblique NPs are relativized on in language $\mathrm{Y}$, then a prediction can be made to the effect that subject, direct object and indirect object NPs also will be relativized on; and so forth. When applied to L2 acquisition data, what this means is that, in accordance with Hawkins's (1987) interpretation of implicational universals, L2 learners will correctly produce or comprehend direct object relativization more often than, or at least as often as, indirect object relativization, and indirect object relativization more often than, or at least as often as, oblique relativization, and so forth. This is precisely the kind of prediction that has been tested in a number of L2 studies of the AH.

\section{Accessibility to Relativization in L2 Acquisition}

As Comrie (1984: 15) observes, the $\mathrm{AH}$ "has spawned a vast amount of relevant literature in the second language acquisition area, showing how the theoretical conclusions reached by Keenan and Comrie (1977) translate fairly directly into valid predictions about the acquisition of relative clauses in a second language, though also noting more specific points where the fit between the two areas is less than perfect". Indeed no other typological properties have been 
investigated in L2 acquisition as thoroughly as has the AH.

It was Gass (1979) who first tested the relevance of the AH to L2 acquisition. She carried out two experiments in which seventeen adult L2 learners of English - with nine different NL backgrounds, Arabic, Chinese, French, Italian, Japanese, Korean, Persian, Portuguese and Thai-were asked to give acceptability judgments to the target language (henceforth TL) sentences with relative clauses and also to perform the task of converting two separate sentences into a single sentence with a relative clause (for subsequent L2 studies of the AH, see Hyltenstam 1984, Pavesi 1986, Doughty 1991, Aarts \& Schils 1995, Croteau 1995). The most important thing that emerged out of these experiments - especially the combining task - was that the L2 learners' ability to form correctly sentences with relative clauses decreased regressively from the highest position (i.e., SBJ) to the lowest position (i.e., OCOMP) on the AH with the exception of GEN. (Note that in Gass's 1979 work the positions of IO and OBL were collapsed into one position due to their analogous behavior in English relative clauses.) $)^{5}$ Thus Keenan \& Comrie's (1977) AH was relatively well validated by Gass's (1979) L2 data.

Further evidence in support of the AH also comes from the fact that in nearly all instances where the L2 learners failed to form relative clauses by not following the instructions given-i.e., "avoidance" in the sense of Schachter (1974) - relative clauses were formed on higher positions on the AH than the intended ones (Gass \& Ard 1984).

\footnotetext{
5 Incidentally, the exceptional behavior of GEN in Gass's (1979) data was taken to be a TL factor in that in English the genitive relative marker whose is "particularly unusual and hence more salient" because it is restricted to GEN. Moreover, Gass (1979) points out that, being positioned immediately after the head noun and before the possessed (e.g., The man whose son just came home. . .), the GEN relative pronoun and the possessed may have been treated as a single unit, thereby functioning either as SBJ or as $\mathrm{DO}$ - positions higher on the $\mathrm{AH}$-in the relative clause. Gass (1979) is of the opinion that this may explain why her L2 learners performed better on GEN than on DO and IO.
} 
In Keenan \& Comrie's (1977) original cross-linguistic survey it was discovered that resumptive pronouns_-pronominal 'copies' of relativized elements in relative clauses - were more likely to be utilized for lower positions than higher positions on the AH. (The use of resumptive pronouns is attested in nonstandard English, e.g., the road that I don't know where it leads (c.f., Comrie 1995: 50).) This was also found to be the case with all the L2 learners of English in Gass's (1979) study irrespective of whether or not their NLs made use of resumptive pronouns in relative clauses (Gass \& Ard 1984). But at the same time L2 learners speaking NLs with the pronounretention strategy (i.e., use of resumptive pronouns in relative clauses) were more likely to employ resumptive pronouns than L2 learners speaking NLs without. Thus there was also evidence in support of the L1 effect of pronoun retention on at least the three highest positions on the AH, i.e., SBJ, DO and IO/OBL. However, insofar as relativization on the two lowest positions on the $\mathrm{AH}$, i.e., GEN and OCOMP, was concerned, no statistically significant differences were noted between the two groups of L2 learners. The use of resumptive pronouns for GEN and OCOMP may thus well be consistent with the predictions of the AH although it cannot be ruled out completely that at least the speakers of languages with the pronounretention strategy may still have been "relying on the patterns of their own NLs" (Gass 1979: 337).

This inverse relationship between the $\mathrm{AH}$ and the use of resumptive pronouns in L2 acquisition of relative clauses, well evident in Gass's data, is further supported generally by Hyltenstam's (1984) investigation of the use of resumptive pronouns in relative clauses by L2 learners of Swedish, with Spanish, Finnish, Greek and Persian as their NLs. In common with English Swedish does not rely on the pronoun-retention strategy and can relativize on every position on the AH, whereas those NLs differ in the positions that can be relativized on and also in the optional and obligatory use of resumptive pronouns. Hyltenstam's results conform well with the predictions of 
the $\mathrm{AH}$, albeit not perfectly. With the positions of GEN and OCOMP inverted, however, the conformity increases to a greater extent (c.f., Gass 1979). Overall, the use of resumptive pronouns in the L2 learners' output is inversely related to the AH with the effect that the frequency of occurrence of resumptive pronouns in relative clauses increases as one moves down the $\mathrm{AH}$.

Hyltenstam's (1984) study also revealed that the frequency of occurrence of resumptive pronouns in the L2 learners' production of Swedish relative clauses was in direct proportion to the degree to which resumptive pronouns are used in relative clauses in their NLs. Persian uses resumptive pronouns for more positions on the AH than does Greek, whereas both Spanish and Finnish completely lack the pronoun-retention strategy. Persian speakers were thus found to make the most extensive use of resumptive pronouns in their production of Swedish relative clauses, followed by Greek, Spanish and Finnish speakers in that order. The point is that the inverse relationship between the $\mathrm{AH}$ and the use of resumptive pronouns in the L2 learners' output notwithstanding the effect of L1 on L2 learners' acquisition of relative clauses was also discernible in Hyltenstam's data, very much as in the case of Gass's original study.

The AH is a chain of implicational universals in that relativizability of any given position on the $\mathrm{AH}$ - of course, except for the topmost position of SBJ-implies relativizability of all positions higher than that position. This implicational nature of the $\mathrm{AH}$ has also prompted some L2 researchers to explore pedagogical implications of the AH for L2 acquisition. Thus Gass (1982) wonders if it is possible to provide L2 learners with relativization instruction only on a low position on the $\mathrm{AH}$ on the assumption that they may be able to make generalizations to the higher positions but not to the lower positions on the AH. This indeed is an intriguing hypothesis, especially in view of the standard pedagogical assumption in at least L2 teaching that instruction on easy structures should precede that on more difficult ones. The question to be asked is whether or not 
L2 learners are able to 'learn' more than they have been taught. If so, it will surely make more sense to teach students difficult structures first so that they can generalize to easy structures on their own than to teach them easy structures first when it is anticipated that they are unable to make similar generalizations to difficult structures.

This particular hypothesis was tested by Gass (1982) by using two groups of ESL (English as Second Language) classes: one experimental group consisting of thirteen ESL students and one control group consisting of five ESL students. The NLs of these ESL students were Arabic, Italian, Persian, Russian and Spanish. First, both the experimental group and the control group were given two test - i.e., grammaticality judgement and production tests - with a view to determining their pre-instructional knowledge of English relativization. The tests revealed that neither group possessed much pre-instructional knowledge of relative clauses; moreover, there was no statistically significant difference between the two groups in terms of performance on the pre-instruction tests. Three days after the tests the experimental group was given instruction only on OBL relativization, whereas the control group was taught along the lines of standard ESL textbooks, that is, instruction first on SBJ, DO and IO relativization, followed by that on GEN relativization with less emphasis. About two days after the conclusion of the instruction the students of the two groups were all tested once again on their knowledge of relativization on all the positions on the AH. The results of the post-instruction tests were quite illuminating. First, the difference between the pre-test and post-test scores of the experimental group was statistically significant, whereas that of the control group was not. Second, with respect to the production task (i.e., combining two separate clauses to form a sentence with a relative clause) the students in the experimental group did generalize from OBL relativization to relativization on the other positions on the $\mathrm{AH}$ with the exception of GEN (c.f., Gass 1979). In the control group, on the other hand, learning was limited only to what they had been 
taught by means of formal instruction. The improvement on the ability of the two groups to relativize on all the positions on the AH between the pre-test and the post-test is summarized in percentage terms in (9) (Gass 1982).

(9) Improvement on the production task in the two groups

\begin{tabular}{lrlr}
\hline \multicolumn{2}{c}{ Control Group } & \multicolumn{2}{c}{ Experimental Group } \\
\hline SBJ & $40 \%$ & SBJ & $30 \%$ \\
DO & $30 \%$ & DO & $39 \%$ \\
IO & $0 \%$ & IO & $42 \%$ \\
OBL & $40 \%$ & OBL & $57 \%$ \\
GEN & $10 \%$ & GEN & $12 \%$ \\
OCOMP & $0 \%$ & OCOMP & $50 \%$ \\
\hline
\end{tabular}

It should also be pointed out, however, that, although the students in the experimental group - as opposed to those in the control group-generalized to the positions other than the one for which they actually received instruction, they did make generalizations not only to higher (or more accessible) positions but also to lower (or less accessible) positions, e.g., OCOMP (c.f., Doughty 1991). This indeed is problematic for the hypothesis that Gass (1982) originally set up for her investigation. Nonetheless there is marked improvement on the pre-test in the post-test in the case of the experimental group, whereby Gass's (1982) hypothesis is well supported. From these results, therefore, Gass (1982: 139) draws an important implication for language pedagogy to the effect that "a more efficacious model for syllabus design. . . would be one in which a more difficult structure preceded an easier one" because L2 learners may come into the classroom, not as passive learners but with the natural abilities to make generalizations from more difficult to less difficult structures. This implication, however, needs to be evaluated in the light of the fact that by definition it takes more time and effort to learn difficult structures than easy ones. 
Eckman, Bell \& Nelson (1988) replicate Gass's (1982) study by further introducing a few elaborations into the latter's testing method and procedures. They carried out their research with three experimental groups instead of one, with each being taught to form relative clauses on only one $\mathrm{AH}$ position, namely SBJ, DO or OBL but, unlike in Gass (1982), they administered no instruction on relativization to the control group. The results of the pre-test were taken into account along with NLs and English proficiency level in order to assign ESL students randomly to one of the four groups. The three experimental groups were then given appropriate instruction on relativization between the two tests, with the control group receiving instruction on sentence combining techniques not related to relative clauses. Two days after the instruction all of the students were given the post-test. The most prominent aspect of the results of the post-test is that the group who performed the best was the OBL group, followed by the DO group, the SBJ group and the control group in that order. Moreover, although the SBJ experimental group generalized somewhat to DO, neither the SBJ group nor the DO group generalized to OBL. Nearly all generalizations were made in the direction of the higher (or more accessible) positions on the $\mathrm{AH}$. These results do indeed seem to confirm the pedagogical hypothesis put forth by Gass (1982). Thus Eckman et al (1988) come to the conclusion that learners actually 'learn' more than they have been taught, thereby challenging the assumption that learners know only what they are taught.

\section{Implications and Suggestions for Esperanto and Other Artificial Languages}

Esperanto draws upon the relative-pronoun strategy in forming relative clauses (Comrie 1995: 49-50): Relative pronouns, which refer back to head nouns, are "moved" to the front of relative clauses, 
and they are also case-marked by means of either a morphological case or a preposition. This relativization strategy is widespread in European languages and is rare outside Europe (Comrie 1989: 147153). Thus relativization in Esperanto is clearly European-based and in fact very similar to that in English (e.g., (3)-(8) vs. (10)-(15)). Indeed this and other European characteristics make Esperanto "less than ideal for (its) stated purpose of being (a vehicle) of communication for the whole world" (Maxwell 1989: 103; also c.f., Comrie 1995 for further discussion). But more importantly, Esperanto is exactly like English in terms of accessibility to relativization: Every grammatical relation on the $\mathrm{AH}$ can be relativized on (Christopher Gledhill, Claude Piron and John C. Wells, pers. comm.). ${ }^{6}$ This is illustrated in (10) to

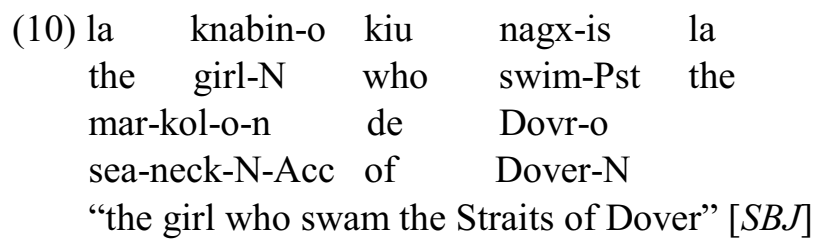

(11) la knabin-o kiu-n la knab-o am-is
the girl-N who-Acc the boy-N love-Pst
per sia tut-a
by means of his whole-Adj heart-N
"the girl whom the boy loved with all his heart" [DO]

The present writer is grateful to Christopher Gledhill, Claude Piron and John C. Wells for answering my questions about relativization in Esperanto, and particularly to John C. Wells for also providing the Esperanto sentences in (10) to (15). The glossing of these sentences has been somewhat simplified, e.g., knabin 'girl' instead of knab-in 'child-feminine'. The following abbreviations are used: Acc = Accusative, $\operatorname{Adj}=$ Adjective, $\mathrm{N}=$ Noun, and Pst $=$ Past. 
128 Language Universals and Universal Language

(12) la knabin-o al kiu la knab-o don-is the girl-N to who the boy-N give-Pst roz-o-n rose-N-Acc "the girl to whom the boy gave rose" $[I O]$

(13) la knabin-o kun kiu la knab-o danc-is the girl-N with who the boy-N dance-Pst "the girl with whom the boy danced' $[O B L]$

(14) la knabin-o kie aut-o-n la sinjorin-o the girl-N whose car-N-Acc the lady-N acxet-is por sia fil-o buy-Pst for her son-N "the girl whose car the lady bought for her son" [GEN]

(15) a bin-o ol kiu la knab-o estas pli the girl-N than who the boy-N is more alt-a tall-Adj "the girl who the boy is taller than" [OCOMP]

As noted in section 3, however, the majority of the languages of the world are not so generous as English or Esperanto in their relativizing possibilities. In fact, there are languages that can relativize only on subject, e.g., Malagasy, and only on subject and direct object, e.g., Luganda, and so on, although there are no languages that cannot relativize on subject.

Can Esperanto then be regarded as structurally neutral in terms of relativizing possibilities? Easy question as this may seem to be, there could in fact be two possible answers: yes and no. One could argue that Esperanto is structurally neutral in terms of relativization, because fluent Esperanto speakers have the option of 'stopping' at 
any point on the $\mathrm{AH}$, depending on less fluent Esperanto speakers' NLs. (Note that it is assumed here that, since "speakers of Esperanto generally show the influence of their mother tongue in their use of Esperanto" (Maxwell 1998: 116), those who are not fluent Esperanto speakers (e.g., so-called 'perpetual learners' or eternaj komencantoj) tend to relativize on as many grammatical relations on the $\mathrm{AH}$ as they do in their NLs.) For instance, if an Esperanto speaker who has perfectly learned to relativize on all the grammatical relations on the AH speaks Esperanto to a less fluent Esperanto speaker of language $\mathrm{X}$, he will be careful (and kind) enough to relativize on subject and direct object only, because in language $\mathrm{X}$ only those two grammatical relations are relativized on. One could then claim that this 'flexibility' is possible, only because Esperanto can relativize on all the grammatical relations on the $\mathrm{AH}$ in the first place. But this is unrealistic because it presupposes that (fluent) Esperanto speakers would know the extent of relativization in every NL spoken by other (less fluent) Esperanto speakers (c.f., Comrie 1995: 57 for a similar point). Moreover, less fluent Esperanto speakers may be required to relativize beyond what is possible in their own NLs when speaking to fluent Esperanto speakers. But it may not always be possible for them to relativize beyond what they can in their NLs.

One could instead argue that Esperanto is not neutral with respect to the languages of the world, because not many languages can relativize as 'generously' as Esperanto does. One could then claim that in order to be neutral in terms of relativization Esperanto should relativize only on what is minimally permitted in the languages of the world, i.e., subject relation, since that grammatical relation can be relativized on in every natural language. But again this will not help spread "the burden of language learning", as there are many languages that relativize on more than subject. In fact, languages that can relativize only on subject are a minority. Esperanto speakers of NLs which relativize on more than subject would have to learn not to relativize on grammatical relations other than subject. This 
too is an unrealistic position to hold.

The foregoing discussion, albeit somewhat simplified or even contrived, points to the impossibility of selecting a structurally neutral 'cut-off position' for relativization (i.e., subject, direct object, indirect object or what?). It raises a fundamental question as to how structural neutrality can be claimed, let alone assessed, in artificial languages when continuum-based properties like the $\mathrm{AH}-$ as opposed to binary properties (i.e., the presence or absence of properties) - are at issue. Whichever grammatical relation of the $\mathrm{AH}$ is chosen as the cut-off point for relativization will necessarily be an arbitrary decision and thus can never be regarded as structurally neutral among the languages of the world. As a matter of fact, it will be meaningless or futile to argue for a particular grammatical relation to be picked as the cut-off point for relativization. This is indeed qualitatively different from the question as to whether artificial languages should or should not have a given structural property (e.g., the definite article $l a$ or the accusative case $-n$ in Esperanto), because, in the case of binary properties, one only needs to choose between having or not having them, for instance, by appealing to the notion of markedness (i.e., the unmarked option preferred to the marked option). Of course, 'arbitrariness' will not be completely ruled out (i.e., at least for speakers of NLs with the marked option), but the decision is much easier to make, and can be made at least on a sound basis. In the case of continuum-based properties, on the other hand, one has to choose from multiple 'options'. The problem is that one option is as good or bad as another, depending on how one looks at it. Indeed the structural neutrality with respect to continuum-based properties is an interesting issue or problem for Esperanto and other artificial languages which aspire to be a vehicle of communication for the whole world.

The L2 acquisition research discussed in section 4, however, can provide some useful ideas as to how the problem of choosing the structurally neutral 'cut-off position' for relativization could be ad- 
dressed, if not resolved. There are two main points arising from these studies, and they are worth summarizing here. First, L2 learners, regardless of their NL backgrounds, had more problems with relativizing on lower than on higher positions - which is what the AH is designed to capture. Second, both Gass (1979) and Hyltenstam (1984) demonstrate clearly that the use of resumptive pronouns in relative clauses is observed in inverse relation to the $\mathrm{AH}$, regardless of whether or not NLs make use of resumptive pronouns in relative clauses: The frequency of occurrence of resumptive pronouns in relative clauses increases as one moves down the AH. Also recall that the TLs, namely English and Swedish, do not rely on the pronoun-retention strategy at all and can relativize on every position on the AH.

The suggestions to be made below on the basis of the preceding two points are not intended for any particular artificial language; they are meant to be general. However, what is going to be suggested for artificial languages already in existence, e.g., Esperanto, is slightly different from what is going to be suggested for future artificial languages. This is intended to minimize the possible effect of the suggestion on the already established norm of Esperanto, for instance.

For artificial languages already in use, the following suggestion can be made:

(16) Resumptive pronouns, in conjunction with the existing relativization strategy, be optionally used for the grammatical relations other than subject.

This is based on the observation that L2 learners tend to make use of resumptive pronouns in relative clauses irrespective of whether their NLs rely on the pronoun-retention strategy or not and also on the fact that every natural language is known to relativize on subject. Relativization on subject will be no serious problem for L2 
learners. In order to spread "the burden of language learning", however, the optional use of resumptive pronouns, which seems to be L2 learners' preferred option, is suggested for the grammatical relations other than subject. In the case of Esperanto, what this means is: Resumptive pronouns will be optionally used in conjunction with the relative-pronoun strategy for the grammatical relations lower than subject. Note that the use of resumptive pronouns is designed to be optional so that fluent Esperanto speakers can have the option of using resumptive pronouns in relative clauses if and when in doubt about the extent of relativization in less fluent Esperanto speakers' NLs. (Again, it is assumed that those who are not fluent Esperanto speakers tend to relativize on as many grammatical relations on the $\mathrm{AH}$ as they do in their NLs.) The use of resumptive pronouns in relative clauses will thus be an open-ended matter and subject to 'negotiation' between Esperanto speakers of different NLs so that less fluent speakers' NLs can be accommodated by fluent speakers. The "burden of language learning" is reduced thereby. There will also be no question of complicating production on the part of fluent Esperanto speakers because of this optional use of resumptive pronouns. The use of resumptive pronouns is the preferred option in L2 acquisition of relative clauses regardless of L2 learners' NL backgrounds. Thus fluent Esperanto speakers would only be asked to carry into their Esperanto speech what they would most probably do when acquiring an L2 (or, in fact, what they may themselves have done before they became fluent in Esperanto). Esperanto speakers of NLs with relativization 'limited' in terms of the $\mathrm{AH}$, on the other hand, can freely use resumptive pronouns when relativizing on lower grammatical relations. In other words, they also would be required to do what they would most probably do when acquiring an L2. The prediction, based on the L2 acquisition studies, is that their use of resumptive pronouns in relative clauses will be in inverse relation to the $\mathrm{AH}$ : more frequent use of resumptive pronouns on lower than higher positions on the AH. Note that this optional use of 
resumptive pronouns also helps preserve the integrity of the relativepronoun strategy, already established in Esperanto.

For artificial languages yet to come into existence, on the other hand, the following suggestion can be made:

(17) The pronoun-retention strategy be the sole relativization strategy.

This is also based on L2 learners' tendency to use resumptive pronouns regardless of whether their NLs rely on the pronoun-retention strategy or not. Since L2 learners do make use of resumptive pronouns in TL relative clauses, the preferred relativization strategy should be the pronoun-retention strategy, which is based on the use of resumptive pronouns. In the case of future artificial languages, there is no established norm to protect or maintain, which explains why there is no restriction imposed on the use of resumptive pronouns with respect to the AH (i.e., the obligatory use of resumptive pronouns regardless of the grammatical relations to be relativized on).

Needless to say, the suggestions in (16) and (17) are speculative -although it is not entirely clear how this can be avoided in topics like the one discussed in this paper - and are meant to be only what they are, i.e., suggestions. Nonetheless the evidence from the L2 acquisition research discussed in section 4 points unequivocally to the use of resumptive pronouns as the preferred structural option in L2 acquisition of relative clauses. Thus it is not inappropriate to take advantage of this important evidence in making suggestions about the preferred relativization strategy for artificial languages such as Esperanto. Artificial languages are learned only as L2s after all. L2 acquisition of artificial languages will be subject to the same constraints or restrictions that L2 acquisition of natural languages is. It will be surprising if otherwise.

Last but not least, the pedagogical implications of the AH for L2 
acquisition of artificial languages such as Esperanto should not be lost sight of, especially because artificial languages are always learned as L2s, most likely, in the context of formal instruction. ${ }^{7}$ One important 'lesson' that Gass (1982) and Eckman et al (1988) provide for formal language instruction is that L2 learners learn more than they are specifically taught. This is something that teachers or instructors of (artificial) languages are well-advised to consider. It is a matter of even greater import for established artificial languages like Esperanto, which relativize on every grammatical relation on the $\mathrm{AH}$.

\section{Conclusion}

This paper has demonstrated that linguistic typology can provide a useful framework in which to assess the structural neutrality of artificial languages such as Esperanto. The structural neutrality of continuum-based properties such as the AH in artificial languages cannot be claimed, let alone assessed, simply because there are multiple options to choose from. No decision is going to be non-arbitrary and can thus be regarded as structurally neutral with respect to the languages of the world. However, linguistic typology, together with L2 acquisition research, can generate some useful ideas as to how this 'problem' can be addressed, if not resolved. It indeed makes specific suggestions on the basis of L2 learners' preferred structural options or strategies. Such suggestions should be taken into account in the development of artificial languages, because these languages also are learned as L2s after all.

\footnotetext{
${ }^{7}$ It will be interesting comparative research to examine how relativization in Esperanto is taught in the context of different L1s. To the best of the present writer's knowledge, there is no published work that deals with this topic.
} 


\section{References}

Aarts, F. \& E. Schils. 1995. Relative Clauses, the Accessibility Hierarchy and the Contrastive Analysis Hypothesis. International Review of Applied Linguistics 33, 47-63.

Blanke, D. 1985. Internationale Planschprachen. Berlin: Akademie Verlag.

Comrie, B. 1984. Why Linguists Need Language Acquirers. In W. Rutherford (ed.), 11-29.

Comrie, B. 1989. Language Universals and Linguistic Typology. Oxford: Blackwell.

Comrie, B. 1995. Natural and Artificial International Languages: A Typologist's Assessment. Proceedings of the Conference on the Need for a Universal Language and Methods of its Creation as Suggested by Hangul 44-66. Seoul: Sejong University.

Croteau, K. 1995. Second Language Acquisition of Relative Clause

Structures by Learners of Italian. In F. Eckman, D. Highland, P. Lee, J. Mileham, \& R. Weber (eds.), Second Language Acquisition and Pedagogy 115-128. Mahwah, NJ:Lawrence Erlbaum.

Crystal, D. 1997. English as Global Language. Cambridge: Cambridge University Press.

Doughty, C. 1991. Second Language Instruction Does Make a Difference: Evidence from an Empirical Study of SL Relativization.

Studies in Second Language Acquisition 13, 431-469.

Eckman, F. 1977. Markedness and the Contrastive Analysis Hypothesis. Language Learning 27, 315-330.

Eckman, F. 1984. Universals, Typologies and Interlanguage. In W. Rutherford (ed.), 79-105.

Eckman, F. 1991. The Structural Conformity Hypothesis and the Acquisition of Consonant Clusters in the Interlanguage of ESL Learners. Studies in Second Language Acquisition 13, 23-41.

Eckman, F., L. Bell, \& D. Nelson. 1988. On the Generalization of Relative Clause Instruction in the Acquisition of English as a 
Second Language. Applied Linguistics 9, 1-20.

Eckman, F., E. Moravcsik, \& J. Wirth. 1989. Implicational Universals and Interrogative Structures in the Interlanguage of ESL Learners. Language Learning 39, 173-205.

Gass, S. 1979. Language Transfer and Universal Grammatical Relations. Language Learning 29, 327-344.

Gass, S. 1982. From Theory to Practice. In M. Hines \& W. Rutherford (eds.), On TESOL 81, 129-140. Washington, DC: TESOL.

Gass, S. 1996. Second Language Acquisition and Linguistic Theory: The Role of Language Transfer. In W. Ritchie \& T. Bhatia (eds.), 317-345.

Gass, S. \& J. Ard. 1980. L2 Data: Their Relevance for Language Universals. TESOL Quarterly 14, 443-452.

Gass, S. \& J. Ard. 1984. Second Language Acquisition and the Ontology of Language Universals. In W. Rutherford (ed.), Language Universals and Second Language Acquisition 33-67. Amsterdam: John Benjamins.

Gass, S. 1989. Language Universals and Second Language Acquisition. Language Learning 39, 497-534.

Gledhill, C. 1998. The Grammar of Esperanto. München: Lincom Europa.

Hawkins, J. 1987. Implicational Universals as Predictors of Language Acquisition. Linguistics 25, 453-473.

Hyltenstam, K. 1984. The Use of Typological Markedness Conditions as Predictors in Second Language Acquisition: The Case of Pronominal Copies in Relative Clauses. In R. Andersen (ed.), Second Languages: A Cross-linguistic Perspective 39-58. Rowley, MA: Newbury House.

Jakobson, R. 1941. Kindersprache, Aphasie, und Allgemeine Lautgesetze. Uppsala: Uppsala Universitets Aarskrift.

Jakobson, R. 1968. Child Language, Aphasia and Phonological Universals. Berlin: Mouton de Gruyter. 
Keenan, E. \& B. Comrie. 1977. Noun Phrase Accessibility and Universal Grammar. Linguistic Inquiry 8, 63-99.

Lapenna, I., U. Lins, \& T. Carlevaro. 1974. Esperanto en Perspektivo. London: Centro de Esploro kaj Dokumentado pri la Monda Lingvo-Problemo.

Maxwell, D. 1989. Principles for Constructing Panned Languages. In K. Schubert (ed.), 101-119.

Pavesi, M. 1986. Markedness, Discoursal Modes, and Relative Clause Formation in a Formal and an Informal Context. Studies in Second Language Acquisition 8, 38-55.

Rutherford, W. (ed.). 1984. Language Universals and Second Language Acquisition. Amsterdam: John Benjamins.

Schachter, J. 1974. An Error in Error Analysis. Language Learning 24, 205-214.

Schubert, K. (ed.). 1989. Interlinguistics: Aspects of the Science of Planned Language. Berlin: Mouton de Gruyter.

Song, J. 2001. Linguistic Typology: Morphology and Syntax. Harlow \& London: Pearson Education.

Swales, J. 1990. Genre Analysis. Cambridge: Cambridge University Press. 